\title{
Electroretinogram responses in myopia: a review
}

\author{
Satish Kumar Gupta - Ranjay Chakraborty (D) Pavan Kumar Verkicharla
}

Received: 14 June 2021/Accepted: 11 October 2021/Published online: 17 November 2021

(C) The Author(s) 2021

\begin{abstract}
The stretching of a myopic eye is associated with several structural and functional changes in the retina and posterior segment of the eye. Recent research highlights the role of retinal signaling in ocular growth. Evidence from studies conducted on animal models and humans suggests that visual mechanisms regulating refractive development are primarily localized at the retina and that the visual signals from the retinal periphery are also critical for visually guided eye growth. Therefore, it is important to study the structural and functional changes in the retina in relation to refractive errors. This review will specifically focus on electroretinogram (ERG) changes in myopia and their implications in understanding the nature of retinal functioning in myopic eyes. Based on the available literature, we will discuss the fundamentals of retinal neurophysiology in the regulation of vision-dependent ocular growth, findings from various studies that investigated global and
\end{abstract}

S. K. Gupta · P. K. Verkicharla ( $\square)$

Myopia Research Lab, Prof. Brien Holden Eye Research Centre, Brien Holden Institute of Optometry and Vision Sciences, Kallam Anji Reddy Campus, L V Prasad Eye Institute, Hyderabad, India

e-mail: pavanverkicharla@lvpei.org

\section{R. Chakraborty}

Caring Futures Institute, College of Nursing and Health

Sciences, Optometry and Vision Science, Flinders

University, Adelaide, South Australia, Australia localized retinal functions in myopia using various types of ERGs.

Keywords Axial length · Electroretinogram (ERG) . Myopia $\cdot$ Neurons $\cdot$ Neurophysiology $\cdot$ Retina

\section{Introduction}

The prevalence of myopia is on the rise worldwide since a few decades [1]. Various meta-analysis studies have predicted that approximately 5 billion of the global population may develop myopia by the year 2050 , with around 1 billion of them having high myopia $[2,3]$. The increasing prevalence of myopia and its associated sight-threatening risks [3-9] make myopia a major public health concern [10-12] and demands investigation into the fundamentals of eye growth regulation. The ocular stretching in myopia is associated with several structural and functional changes in posterior segment of the eye [13, 14]. Recent research highlights the role of retinal signaling in ocular growth, and various studies have investigated the electrophysiological responses in different types of refractive errors. This review is aimed to provide a summary of research work on electroretinogram (ERG) responses in myopia and their implications in understanding the nature of retinal functioning in myopic eyes. 


\section{Retinal development, photo-transduction, and regulation of vision-dependent ocular growth}

The development of neural retina usually begins on day 26 of gestation [15], where the inner neural ectoderm divides into 3-4 layers of cells [16]. By week 12, the retinal layers start to form, with the inner neuroblastic layer giving rise to the ganglion, amacrine, and Muller cells creating the inner retina [17]. Similarly, the outer neuroblastic layer gives rise to photoreceptors (rods and cones), bipolar and horizontal cells forming the outer retina [17]. By the end of week 14, the ganglion cells migrate away from the fovea toward retinal periphery and cone photoreceptors migrate toward the fovea $[16,18]$.

Retina being the only photo-sensitive neural layer in the eye [19], incorporates about 55 types of structurally and functionally specific neurons $[20,21]$ including photoreceptors, bipolar cells, ganglion cells, horizontal cells, and amacrine cells $[22,23]$. The distinct arrangement of these neurons from outer to inner retina forms a complex circuit to capture the photons of light from an object [24-26]. These photons are converted into electrical/neuronal signals by the photoreceptors with the help of visual pigments present in them by a process called "phototransduction" [26, 27]. The retinal photoreceptors, through synapses with retinal bipolar cells, transmit signals to the retinal ganglion cells. Upon activation, the axons of retinal ganglion cells carry neuronal signals to the brain via optic nerve for visual perception [28]. Evidence from animal studies suggests that both inner and outer retina may influence the detection of optical defocus and signaling for the corresponding development of ocular growth [19, 29-34].

Several animal species including chicks [35-44], squid [45], tree shrews [33, 46], monkeys [47-55], marmosets [56], guinea pigs [57], kittens [58-60], mice [61-63], and also humans [64-68] are capable of identifying the sign and magnitude of retinal image defocus and make compensatory alterations in ocular growth [69-74]. Evidence from the experiments conducted on animal models indicates that the absence of input from the accommodative system (cycloplegia, ciliary nerve section, or damage to the EdingerWestphal nucleus) [31, 39] or higher visual center (optic nerve section) [75] does not influence the ocular response to imposed form-deprivation [38, 75], or optical defocus $[31,39,42,75,76]$, suggesting that the visual mechanisms regulating the refractive development are primarily localized at the retina.

Given that the fovea provides the best visual acuity (largely attributed to cone signaling) [77, 78], it was traditionally assumed that cone pathways may have a greater influence on visual signaling for refractive development [70, 79]. However, as the foveal area corresponds to only a small part of the visual field, it is reasonable to assume that the peripheral retinal areas might also be important in driving refractive status. There is growing evidence involving animal models indicating the presence of ocular growth pathways mediated by signals from the peripheral retina. The normal response to a) form-deprivation in monkeys treated with laser ablation at the cone-rich fovea [52], b) similar myopic responses in monkeys with formdeprivation [48, 53] and hyperopic defocus [51, 54] imposed on the rod-dominated peripheral regions or the entire visual field, and c) recent work on Gnat $1^{-1-}$ mice with rod dysfunction [63] indicate that the peripheral rod pathways may be equally critical for visually guided eye growth. Blocking the functions of photoreceptors [19, 80], ON and OFF pathways $[60,81-83]$ by pharmacological means (neurotoxins) $[30-32,34]$ or genetic means (such as in mouse models) [84-88] is known to affect both normal refractive development and response to form-deprivation myopia (FDM) showing the importance of various retinal neurons, neuronal pathways, and neurotransmitters in the refractive development of eye [89, 90]. Overall, these studies support the hypothesis that refractive development occurs through a cascade of local and regionally selective mechanisms in the retina $[55,70,73,74,79]$.

\section{Electroretinogram (ERG)}

The retinal function can be assessed by electrophysiological tests that study the electrical properties of the biological cells and tissues, driven by the flow of ions (ion current) [26, 91-93]. Of various electrophysiological tests, the electroretinogram (ERG) with the standard protocol by the International Society for Clinical Electrophysiology of Vision (ISCEV) is widely used to determine the global and localized retinal responses [94-97]. When a bright flash of light illuminates the retina, changes in membrane potentials 
across the neuronal and non-neuronal retinal cells simultaneously and instantaneously with a high temporal resolution (milliseconds) [94-97] give rise to an extracellular current, which forms the basis of ERG [98-100]. Hence, the ERG test provides a unique opportunity to investigate changes in retinal electrical activity to several inherited and acquired retinal diseases [94-97] and several disorders or ocular conditions including refractive errors [101]. The most commonly used ERG techniques are full-field flash ERG (ffERG), multifocal ERG (mfERG), and pattern ERG (PERG).

\section{Full-field flash electroretinogram (ffERG) and its responses in myopia}

A flash ERG measures the average response of retinal cells from a relatively broad retinal region to a fullfield luminance stimulation [94]. By varying the background illumination, the light- or dark-adapted state of the eye, and the intensity of stimulus flash, one can elicit and isolate responses from different retinal cells. A standard ERG waveform is usually biphasic, with an initial cornea-negative response (a-wave), followed by a cornea-positive response (b-wave), and an additional slower positive wave or c-wave (Fig. 1a: scotopic and Fig. 1c: photopic) [97, 102]. In general, electrical activity in the photoreceptors, ON-bipolar cells, and retinal pigment epithelium initiate the a-wave [103], b-wave [104], and c-wave [102], respectively. The oscillatory potentials (OPs) that indicate the activity of amacrine cells in inner retina are represented by a small high-frequency wavelet component on the ascending limb of b-waves [94].

The results from several studies that investigated ffERG responses in myopia are given in Table 1. The overall incidence of abnormal electrophysiological findings in myopes younger than 18 years of age was reported to be $29 \%$, with a higher proportion of ERG abnormalities reported in higher ametropias (spherical equivalent refractive error, SER worse than \pm 6.00 D; 52\%) compared to individuals with emmetropia (SER: $-0.75 \mathrm{D}$ to $+1.50 \mathrm{D} ; 26 \%$ ) or low ametropia (SER lower than $\pm 6.00 \mathrm{D}$ ) [101].

Since the first report of conventional ERG in myopes by Karpe in 1945 [105], various studies have reported impairment of retinal function in myopia. Several studies reported a significant reduction of b-wave amplitude in myopia that closely correlated with the degree of myopia and the axial length of eye [106-115]. For every 1-mm increase in axial length, the dark-adapted 3.0 ERG showed a reduction of $15.7 \mu \mathrm{V}$ and $23.4 \mu \mathrm{V}$ in a-wave and b-wave amplitude, respectively, in an absence of a myopic retinal degeneration [109]. Significant differences in both aand b-wave amplitudes of ffERG have been reported in high myopia (SER: $-6.00 \mathrm{D}$ to $-14.50 \mathrm{D}$ ),

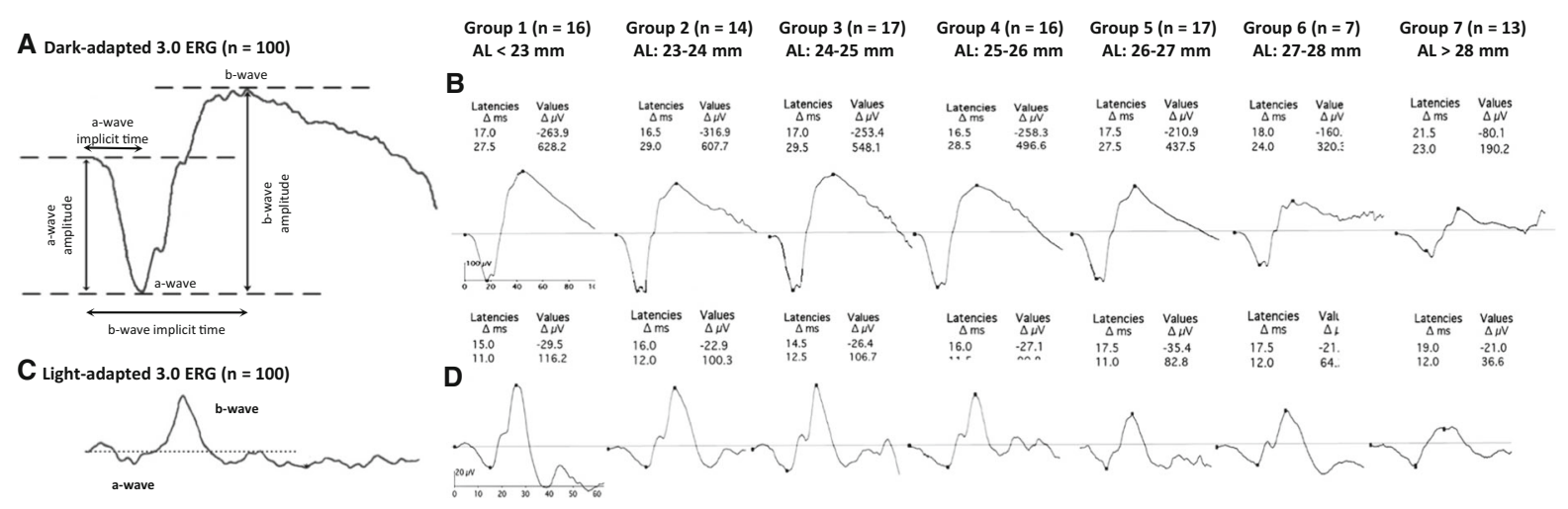

Fig. 1 Normal waveforms and parameters of $\mathbf{A}$ dark-adapted 3.0 ERG and C light-adapted 3.0 ERG of full-field electroretinogram (ffERG). Average ffERG responses from $\mathbf{B}$ darkadapted 3.0 ERG and D light-adapted 3.0 ERG from 100 eyes with axial length (AL) ranging from 21.79 to $30.55 \mathrm{~mm}$ and spherical equivalent refractive error (SER) ranging from +0.50 to $-18.00 \mathrm{D}$. All participants were divided into seven different groups based on their mean AL: Group 1 (22.40 mm), Group 2
(23.10 mm), Group 3 (24.26 mm), Group 4 (25.51 mm), Group $5(26.34 \mathrm{~mm})$, Group $6(27.5 \mathrm{~mm})$, and Group 7 (29.55 $\mathrm{mm})$. The two values listed for each group under latencies and values, respectively, indicate the change $(\Delta)$ in latencies $(\Delta \mathrm{ms})$ and amplitudes $(\Delta \mu \mathrm{V})$ of a ffERG a-wave (negative values) and b-wave (positive values). Adapted with permission from Sachidanandam et al. (2017) [109] 
moderate myopia ( $-3.00 \mathrm{D}$ to -5.00$)$, and low refractive error $(+0.75 \mathrm{D}$ to $-2.75 \mathrm{D})[108,110]$ with a significant reduction in the b-wave amplitude under both scotopic (Fig. 1b) and photopic (Fig. 1d) conditions for individuals with high myopia (Fig. 2) [106, 107, 110, 111]. Scotopic responses (darkadapted 3.0 ERG) were, however, reported to be more significantly affected than the photopic responses (light-adapted 3.0 and $30 \mathrm{~Hz}$ flicker ERG) [109, 110].

Studies have shown significantly lower short (S), long (L) and middle (M) wavelength-sensitive cone ERG b-wave amplitudes in high myopic eyes than the non-myopic eyes [116]. Significant reduction of cone and rod responses (mostly cones) in individuals with

Table 1 Summary of studies on full-field flash ERG (ffERG) and myopia

\begin{tabular}{ll}
\hline References & Participants \\
\hline Blach et al. & $\begin{array}{c}25 \text { emmetropes and 30 high myopes with degenerative } \\
\text { [119] }\end{array}$ \\
Malik & 43 myopes with degenerative fundus changes and 37 \\
et al.[112] & myopes with normal fundus
\end{tabular}

Perlman et al.

Ishikawa et al. [120]

Westall et al. [108]

Yoshii et al. [113]

Flitcroft et al. [101]

Shamshinova et al. [111]

Kader et al. [106]

Wang et al. [117]

Koh et al. [110]

Sachidanandam et al. [109]

Wan et al. [122] 19 emmetropes $( \pm 0.25 \mathrm{D}), 18$ low myopes $(-0.50$ to $-3.00 \mathrm{D}), 23$ moderate myopes $(-3.25$ to -6.00 $\mathrm{D})$, and 16 high myopes $(\leq-6.25 \mathrm{D})$

15 high myopes $(\leq-6.00 \mathrm{D}), 19$ low myopes $(-0.75$ to $-6.00 \mathrm{D}), 35$ emmetropes $(-0.75$ to $+1.50 \mathrm{D})$, 44 low hyperopes $(+1.50$ to $+6.00 \mathrm{D})$, and 10 high hyperopes $(\geq+6.00 \mathrm{D})$

46 myopes with moderate-to-high congenital myopia

40 emmetropes $( \pm 0.25 \mathrm{D}), 20$ mild myopes $(-0.50$ to $-3.00 \mathrm{D}), 28$ moderate myopes $(-3.25$ to -6.00 D), 40 high myopes ( -6.25 to $-15.00 \mathrm{D})$, and 40 pathological myopes $(-7.00$ to $-22.00 \mathrm{D}$ with 7 posterior staphyloma)

64 early-onset high myopes and 20 late-onset high myopes

32 myopes $(\leq-6.00 \mathrm{D})$

100 eyes with axial length ranging from 21.79 to $30.55 \mathrm{~mm}$ and SER ranging from +0.50 to -18.00 D

\section{Outcomes}

Increased a-wave and reduced b-wave amplitude with increased degree of myopia

Reduced a- and b-wave amplitudes as the degree of myopia increased. Decreased ffERG responses in the eyes with degenerative fundus changes, irrespective of the degree of myopia

Reduced scotopic a-and b-wave and photopic b-wave amplitudes in high myopes

Reduced a-and b-wave amplitudes in tigroid fundus. Reduced a- and b-wave, and OPs' amplitudes and increased implicit time in posterior staphyloma involving the macula

Reduced rod-cone a-and b-wave, cone b-wave, and OPs' amplitudes in high myopes, which was proportional to increased AL

Reduced nonlinear component of the ERG amplitudes from the posterior pole of the fundus in high myopes

Abnormal ffERG responses in high ammetropia

\section{with increased AL}

Reduced b-wave amplitude with increased degree of myopia and AL

Reduced scotopic, photopic, and combined b-wave, OPs', and $30 \mathrm{~Hz}$ flicker amplitudes as well as delayed latencies in high myopes, which was proportional to increased $\mathrm{AL}$

Reduced scotopic b-wave, photopic a- and b-wave, and combined a- and b-wave amplitudes in early-onset high myopes

Reduced scotopic b-wave, photopic a- and b-wave, and $30 \mathrm{~Hz}$ flicker b-wave amplitudes with increased degree of myopia and AL

Increased scotopic a- and b-wave amplitudes as well as rod-driven OPs' peak frequency with increased degree of myopia

$A L$ Axial length, ERG Electroretinogram, ffERG full-field flash electroretinogram, IT implicit time, $O P S$ oscillatory potentials, $S E R$ spherical equivalent refractive error 

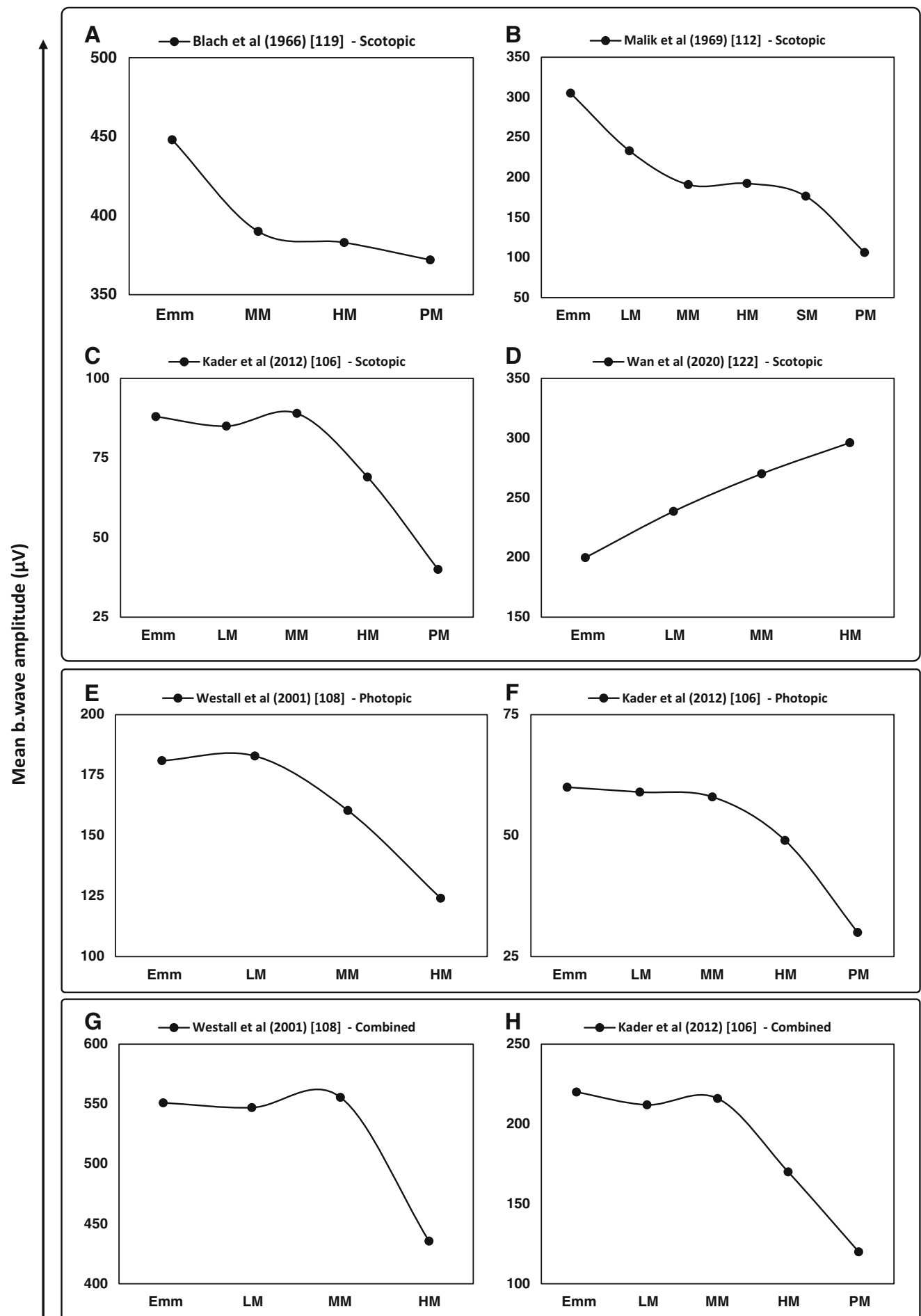

Refractive group

Fig. 2 Mean b-wave amplitudes for scotopic (A-D), photopic $(\mathbf{E}, \mathbf{F})$, and combined response $(\mathbf{G}, \mathbf{H})$ of full-field flash ERG (ffERG) reported by each study in emmetropia (Emm) and various grades of myopia ( $L M$ : low myopia, $M M$ : moderate myopia, $H M$ : high myopia, $S M$ : severe myopia, and $P M$ : pathological myopia) 
early-onset of high myopia (onset age, $\leq 5$ years) than those with late-onset of high myopia (onset age, $12.4 \pm 2.5$ years) suggests that cone-rod dysfunction may be a sign for early onset of high myopia $[117,118]$. The ffERG [119] and focal macular ERG [120] findings in pathologic myopes (presence of myopic retinal degeneration caused by progressive stretching and thinning of posterior segment of eye due to excessive axial length elongation which can result in reduced best-corrected visual acuity $[12,121])$ showed a significant reduction in the amplitude of a- and b-wave in high myopic eyes with tigroid fundus appearance when compared to emmetropic eyes, whereas the implicit time was within the normal range. Similarly, there was a significant reduction in the amplitude of a-wave, b-wave, and OPs and delay in implicit time in high myopia with posterior staphyloma involving the macula compared to early myopia with tigroid fundus [120]. The reduced amplitude with normal implicit time in high myopia with tigroid fundus was related to a significant reduction in the macular cone density (focal macular ERG), which is considered to be an early macular change in high myopia [119, 120]. Furthermore, it was suggested that the reduced amplitude with delayed latency in high myopia associated with macular pathologies such as posterior staphyloma involving the macula could further reduce macular cone photoreceptors [120]. Likewise, chorioretinal vascular changes, retinal pigment epithelium degeneration, and receptor changes found in degenerative myopia may also play a major role in altering the ERG responses [119].

In contrast, Wan et al. (2020) recently reported an increase in the amplitude of a- and b-wave of the scotopic/dark-adapted 3.0 ERG (combined responses arising from the photoreceptors and ON-bipolar cells of both the rod and cone systems; rod-dominated) with the degree of myopia [122]. In addition, the average peak frequency of the rod-driven dark-adapted OPs arising from amacrine cells and the inner plexiform layer also showed a significant positive correlation with the magnitude of myopia [122]. The authors argued that these inconsistencies in comparison with other studies reflected the composition of the participants in their study, being young adults without any sign of pathological myopia (i.e., myopic retinal degenerations). In addition, the responses obtained from previous studies reflected combined contributions of the rod- and cone-driven OPs, interfering with each other [123-126], while Wan et al. isolated the rod-driven OPs by subtracting the lightadapted ERG from the dark-adapted ERG [127, 128]. Their findings indicate an alteration in the rod and ONbipolar cell function in myopia, with minimal effect on the cone system. It is hypothesized that changes in the rod-mediated retinal function may be related to the changes in the retinal dopaminergic pathways (dopamine D2 receptors) [122, 129]. The variation in the dark-adapted 3.0 ERG OP amplitudes in myopes indicates an imbalance of the 'ON' and 'OFF' retinal activity, which may be associated with the development of myopia and its progression [130].

\section{Multifocal electroretinogram (mfERG) and its responses in myopia}

A conventional ffERG measures the global electrical response of the entire retina, but it does not provide a localized response [131]. A mfERG is applicable for objectively studying local retinal health as well as characterizing and monitoring focal retinal lesions in various pathological conditions [132-134]. The mfERG uses a specific hexagonal stimulus pattern to obtain a topographic map of retinal electrophysiological activity over a restricted retinal region ( $\left.\sim 40-50^{\circ}\right)$, unlike ffERG, that reflects light-induced electrical activity from almost the entire retina [95]. This specific hexagonal pattern stimulus illuminates the retina using a pseudo-random binary m-sequence algorithm and gives rise to a continuously recorded signal from individual retinal locations [95]. All the localized responses can be averaged to compare quadrants, hemi-retinal areas, normal and abnormal regions of the two eyes, or successive rings from center to periphery [95]. Routinely, the stimulus pattern (array) with 61 or 103 hexagons is used within a field diameter of $40-50^{\circ}\left(20-25^{\circ}\right.$ radius from the point of fixation to the edge of display) [95]. In the case of 61 hexagons, they are grouped from center to periphery into five rings (R1-R5), where R1 is the central ring and R5 is the peripheral ring. The approximate eccentricity from $\mathrm{R} 1$ to $\mathrm{R} 5$ is $<2^{\circ}$, $2-5^{\circ}, 5-10^{\circ}, 10-15^{\circ}$, and $>15^{\circ}\left(\sim 23^{\circ}\right)$, respectively [135]. A similar grouping for 103 hexagons display would have a total of six rings within the same field diameter. 
A typical mfERG waveform (also called the firstorder response, or first-order kernel) is analogous to the conventional ffERG response as it is biphasic, with an initial negative component (N1), followed by a positive peak (P1) (Fig. 3a) [95]. There is another second negative deflection (N2) after the positive peak (P1). In humans, the N1 component primarily originates from the cone photoreceptors with minimal contribution from ON- and OFF-cone bipolar cells, the $\mathrm{P} 1$ component arises from the activity of $\mathrm{ON}-$ and OFF-cone bipolar cells, and the N2 component is derived from inner retinal cells (amacrine and ganglion cells) [94, 95, 136, 137].

The results from several studies that investigated mfERG responses in myopia are given in Table 2. Previous investigations on early changes in retinal function using the first-order kernel responses in low, medium, and high myopes showed a significant reduction of N1, P1 [106, 109-111, 138-143], and N2 amplitude density [139] with a greater effect on P1 amplitudes than N1 amplitudes (Fig. 3b and Fig. 4) [109, 143, 144]. The reduction in N1 and P1 amplitude density and significant delay in corresponding latencies $[145,146]$ in all rings, as well as four retinal quadrants, was significantly correlated with axial length and the degree of myopic refractive error [106, 109-111, 138-144]. The delayed implicit time was attributed to the possible altered synaptic transmission between the ON- and OFF-bipolar cells or structural changes in the inner plexiform layer of retina [147].
Previous studies have found that the mfERG amplitude density are maximum, and the latencies of P1 and N2 waves are the longest at the central R1 (fovea), which progressively decreased with the increase in retinal eccentricity [135, 138, 142, 148]. However, P1 amplitude density reduction in case of children with progressive myopia $(<-1.00 \mathrm{D} /$ 2 years) was reported to be significantly smaller than stable myopes at central 5 degrees (R1) [149]. Progressive myopes also showed significantly shorter implicit times for OPs arising from inner retina compared to emmetropes and stable myopes, with similar implicit times for stable myopes and emmetropes [150]. These findings collectively indicate that progression of myopia may lead to inner retinal changes and alter the electrophysiological responses at both center and periphery of the retina [150].

There are various other factors such as optical, electrical, and retinal factors that contribute to the reduced mfERG responses. For optical factors, the degraded mfERG responses are associated with the decreased retinal image size and retinal illuminance due to elongated axial length in myopes. Electrical factors such as increased electrical path and ocular resistance from the electrical sources (at retinal plane) and the ERG electrodes [151] and lower retinal cell responsivity are proposed to be linked with reduced mfERG responses in myopes [152]. Retinal factors attributing to the reduced $\mathrm{mfERG}$ responses in myopes are increased sub-retinal space and morphological alterations in retinal cells due to axial elongation $[153,154]$. Morphological changes include decreased
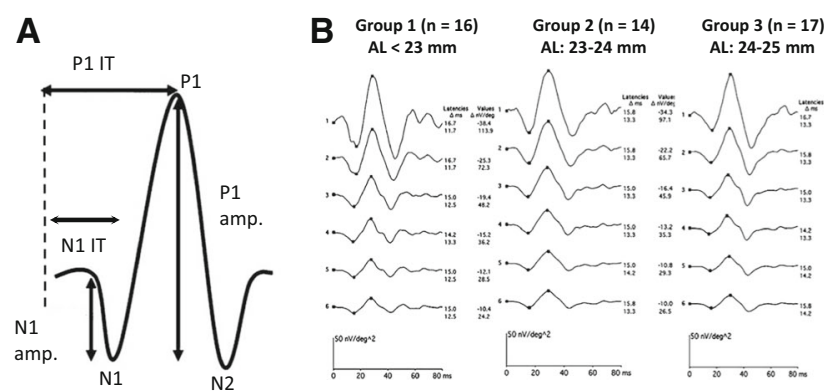

Fig. 3 A Normal multifocal electroretinogram (mfERG) waveform and parameters. B Average six mfERG ring responses from 100 eyes with axial length (AL) ranging from 21.79 to $30.55 \mathrm{~mm}$ and spherical equivalent refractive error (SER) ranging from +0.50 to $-18.00 \mathrm{D}$. All participants were divided into seven different groups based on their mean AL: Group 1 (22.40 mm), Group $2(23.10 \mathrm{~mm})$, Group 3
(24.26 mm), Group 4 (25.51 mm), Group 5 (26.34 mm), Group $6(27.5 \mathrm{~mm})$, and Group $7(29.55 \mathrm{~mm})$. The two values listed for each group under latencies and under values, respectively, indicate the change $(\Delta)$ in latencies $(\Delta \mathrm{ms})$ and amplitude density $\left(\Delta \mathrm{nV} / \mathrm{deg}^{2}\right)$ of a mfERG N1 (negative values) and P1 (positive values) wave. Adapted with permission from Sachidanandam et al. (2017) [109] 
Table 2 Summary of studies on multifocal ERG (mfERG) and myopia

\begin{tabular}{ll}
\hline References & Participants \\
\hline $\begin{array}{c}\text { Kawabata et al. } \\
{[138]}\end{array}$ & $\begin{array}{l}10 \text { emmetropes/low myopes }(+1.00 \text { to }-3.00 \mathrm{D}), 10 \\
\text { moderate myopes }(-3.25 \text { to }-6.00 \mathrm{D}), 10 \text { high } \\
\text { myopes }(\leq-6.25 \mathrm{D})\end{array}$
\end{tabular}

Sun et al. [148] 20 emmetropes, 20 mild myopes, 20 moderate myopes, and 20 high myopes

Chan et al.

[158]

Luu et al. [139] 104 children and 31 adults with SER ranging from 0.00 to $-10.00 \mathrm{D}$

Luu et al. [149] 12 myopes with a high myopia progression rate $(<-1.00 \mathrm{D} / 2$ years $), 44$ myopes with a moderate progression rate $(-0.25$ to $-1.00 \mathrm{D} / 2$ years), and 25 myopes with no progression or a low progression rate $(-0.25 \mathrm{D} / 2$ years $)$

Chen et al. $\quad 10$ emmetropes $( \pm 0.75 \mathrm{D})$ and 18 myopes $(-0.75$

[146] to $-9.50 \mathrm{D})$ with 9 stable and 9 progressive myopes $(\leq-0.50 \mathrm{D} / 2$ years $)$

Chen et al. [150]

Chen et al. [145]

Wolsley et al. [160]

Ying et al. [144] 12 pathological myopes $(\mathrm{AL} \geq 30.00 \mathrm{~mm})$ and 24 pathological myopes $(\mathrm{AL}<30.00 \mathrm{~mm})$

Shamshinova et al. [111]

Kader et al. [106]

Azad et al. [135]

Park et al. [141] 30 mild myopes ( -0.50 to $-2.75 \mathrm{D}), 25$ moderate myopes $(-3.00$ to $-5.75 \mathrm{D}), 17$ high myopes ( -6.00 to $-9.75 \mathrm{D})$, and 18 super high myopes $(-10.0$ to $-15.0 \mathrm{D})$

Koh et al. [110] 32 myopes $(\leq-6.00 \mathrm{D})$
Outcomes

Reduced N1, P1 amplitudes and delayed corresponding latencies with increased degree of myopia and retinal eccentricity

Reduced N1, P1, N2 amplitudes and corresponding response density with increased degree of myopia and retinal eccentricity

Reduced P1 amplitude in the central (R1) and reduced $\mathrm{N} 1, \mathrm{P} 1$ amplitudes in the paracentral region (R3) with increased degree of myopia and AL. The mfERG amplitude reduced by about $6-10 \%$ per $1-\mathrm{mm}$ increase in $\mathrm{AL}$

Reduced N1, P1, N2 amplitudes and delayed corresponding IT with increased degree of myopia in adults

Reduced P1 amplitude within the central 5 degrees (R1) in the children with high myopia progression

Reduced P1, N2 amplitudes and P1 implicit time within the paracentral retina (R2) in myopes. AL contributed to $17 \%$ of the variance in $\mathrm{mfERG}$ responses

Reduced OPs' IT in progressive myopes

Delayed P1 IT in stable and progressive myopes. AL contributed to $15 \%$ of the variance in IT, while SER accounted for $27 \%$

Reduced P1 amplitude and delayed P1 IT, with increased retinal eccentricity in high myopes

Reduced P1 amplitude, which was proportional to the neural retinal thickness in all quadrants and rings with increased $\mathrm{AL}$

Reduced P1 amplitude in all rings with increased degree of myopia and AL

Reduced P1 amplitude and delayed P1 IT with increased degree of myopia, AL, and retinal eccentricity

Maximum N1, P1, N2 amplitudes, and longest P1, N2 latencies at the fovea, which progressively decreased with increased retinal eccentricity

Reduced N1, P1 amplitudes and delayed P1 IT with increased degree of myopia and retinal eccentricity

Reduced P1 amplitude in the outer rings (R3-R5) with increased $\mathrm{AL}$ 
Table 2 continued

\begin{tabular}{|c|c|c|}
\hline References & Participants & Outcomes \\
\hline Song et al. [142] & $\begin{array}{l}31 \text { emmetropes }(+0.75 \text { to }-0.50 \mathrm{D} ; \mathrm{AL}: 22 \text { to } \\
24 \mathrm{~mm}), 26 \text { low-to-moderate myopes }(-0.50 \\
\text { to }-6.00 \mathrm{D} ; \mathrm{AL}: 24 \text { to } 26 \mathrm{~mm}), 34 \text { high myopes } \\
(-6.00 \text { to }-10.00 \mathrm{D} ; \mathrm{AL}: 26 \text { to } 28 \mathrm{~mm}), 22 \text { super } \\
\text { high myopes }(<-10.00 \mathrm{D} ; \mathrm{AL}:>28 \mathrm{~mm})\end{array}$ & $\begin{array}{l}\text { Reduced P1 amplitude, P1 amplitude density, and } \\
\text { delayed P1 IT with increased degree of myopia, AL, } \\
\text { and retinal eccentricity }\end{array}$ \\
\hline $\begin{array}{l}\text { Sachidanandam } \\
\text { et al. [109] }\end{array}$ & $\begin{array}{l}100 \text { eyes with axial length ranging from } 21.79 \text { to } \\
30.55 \mathrm{~mm} \text { and SER ranging from }+0.50 \text { to }-18.00 \\
\text { D }\end{array}$ & $\begin{array}{l}\text { Reduced N1, P1 amplitudes and minimal delayed } \\
\text { corresponding IT with increased AL }\end{array}$ \\
\hline $\begin{array}{l}\text { Ismael et al. } \\
\text { [140] }\end{array}$ & $\begin{array}{l}20 \text { emmetropes }( \pm 0.50 \mathrm{D}), 20 \text { mild myopes }(-0.50 \\
\text { to }-3.00 \mathrm{D}), 20 \text { moderate myopes }(-3.00 \text { to }-6.00 \\
\mathrm{D}) \text {, and } 20 \text { high myopes }(<-6.00 \mathrm{D})\end{array}$ & $\begin{array}{l}\text { Reduced P1 amplitude, delayed P1 latency in all rings } \\
\text { as well as reduced N1, P1 amplitudes, delayed N1 } \\
\text { latency in all quadrants with increased degree of } \\
\text { myopia, AL, retinal eccentricity, and RNFL thinning }\end{array}$ \\
\hline $\begin{array}{l}\text { El-Gamal et al. } \\
\text { [143] }\end{array}$ & $\begin{array}{l}30 \text { emmetropes }( \pm 0.25 \mathrm{D}) \text { and } 30 \text { high myopes } \\
(\leq-5.00 \mathrm{D} \text { and } \mathrm{AL}>26 \mathrm{~mm})\end{array}$ & $\begin{array}{l}\text { Reduced N1, P1 amplitudes and corresponding IT at } \\
\text { almost all rings and quadrants in high myopes, which } \\
\text { was proportional to increased AL. P1 responses were } \\
\text { more affected }\end{array}$ \\
\hline $\begin{array}{l}\text { Nebbioso et al. } \\
\text { [162] }\end{array}$ & $\begin{array}{l}24 \text { emmetropes, } 24 \text { high myopes }(<-8.00 \mathrm{D} \text { and } \\
\mathrm{AL}>26 \mathrm{~mm}) \text { with } \mathrm{MF} \text {, and } 24 \text { high myopes without } \\
\mathrm{MF}\end{array}$ & $\begin{array}{l}\text { Reduced P1 amplitude and delayed P1 IT with } \\
\text { increased macular thickness in high myopes with MF }\end{array}$ \\
\hline
\end{tabular}

$A L$ axial length, ERG electroretinogram, IT implicit time, $m f E R G$ multifocal electroretinogram, $M F$ myopic foveoschisis, $O P s$ oscillatory potentials, $R 1-R 5$ ring 1 to ring 5 from center to periphery, RNFL retinal nerve fiber layer, $S E R$ spherical equivalent refractive error

retinal thickness, decreased retinal photoreceptor density [155], structural changes in photoreceptor outer segment [19], and photoreceptor dysfunction [156]. The prolonged implicit times/delayed latency may also be due to altered synaptic transmission from retinal photoreceptors (primarily rods) to $\mathrm{ON}$ and OFF pathways [157].

\section{Influence of axial length on mfERG responses}

Similar to ffERG, the mfERG amplitude density also shows a better correlation with axial length compared to refractive error [109, 110], which is the most important determinant of myopic mfERG responses across all five rings [140]. For every 1-mm increase in axial length, the mfERG at R1 (fovea) showed a reduction of $2.4 \mathrm{nV} / \mathrm{deg}^{2}$ and $7.4 \mathrm{nV} / \mathrm{deg}^{2}$ in N1 and $\mathrm{P} 1$ amplitude density, respectively, in an absence of a myopic retinal degeneration [109]. High myopes with longer axial length had decreased mfERG responses across central, paracentral [158], and outer rings (R3R5) [110]. The central retina shows higher rates of reduction in both $\mathrm{N} 1$ and $\mathrm{P} 1$ amplitude density [109, 158]. The mean N1 and P1 mfERG amplitude density responses were reported to decrease by $6-10 \%$ per mm of axial length elongation [158]. Axial length accounted for $15 \%$ of the total variance in implicit time, while refractive error accounted for 27\% [145].

Given that the mfERG responses primarily arise from retinal bipolar cells and nuclear layer, any physical or mechanical alterations to these cells will have an impact on mfERG responses [147]. Hood et al. indicated that an extensive global loss of bipolar cells essentially abolishes the overall mfERG response, whereas a localized loss exhibits a selective and localized reduction in the mfERG amplitudes with a mild-to-moderate increase in the implicit time and delayed latency [147].

Influence of myopic retinal changes on mfERG responses

The mfERG responses gradually decline toward the periphery [159] and correlate with peripheral retinal thinning in moderate and high myopes $[135,141,144,160,161]$. Retinal thinning in moderate and high myopes, due to reduced middle to inner retinal (MIR) layer (from outer plexiform layer to retinal nerve fiber layer (RNFL)) thickness, was correlated with decreased spatial resolution, reduced 


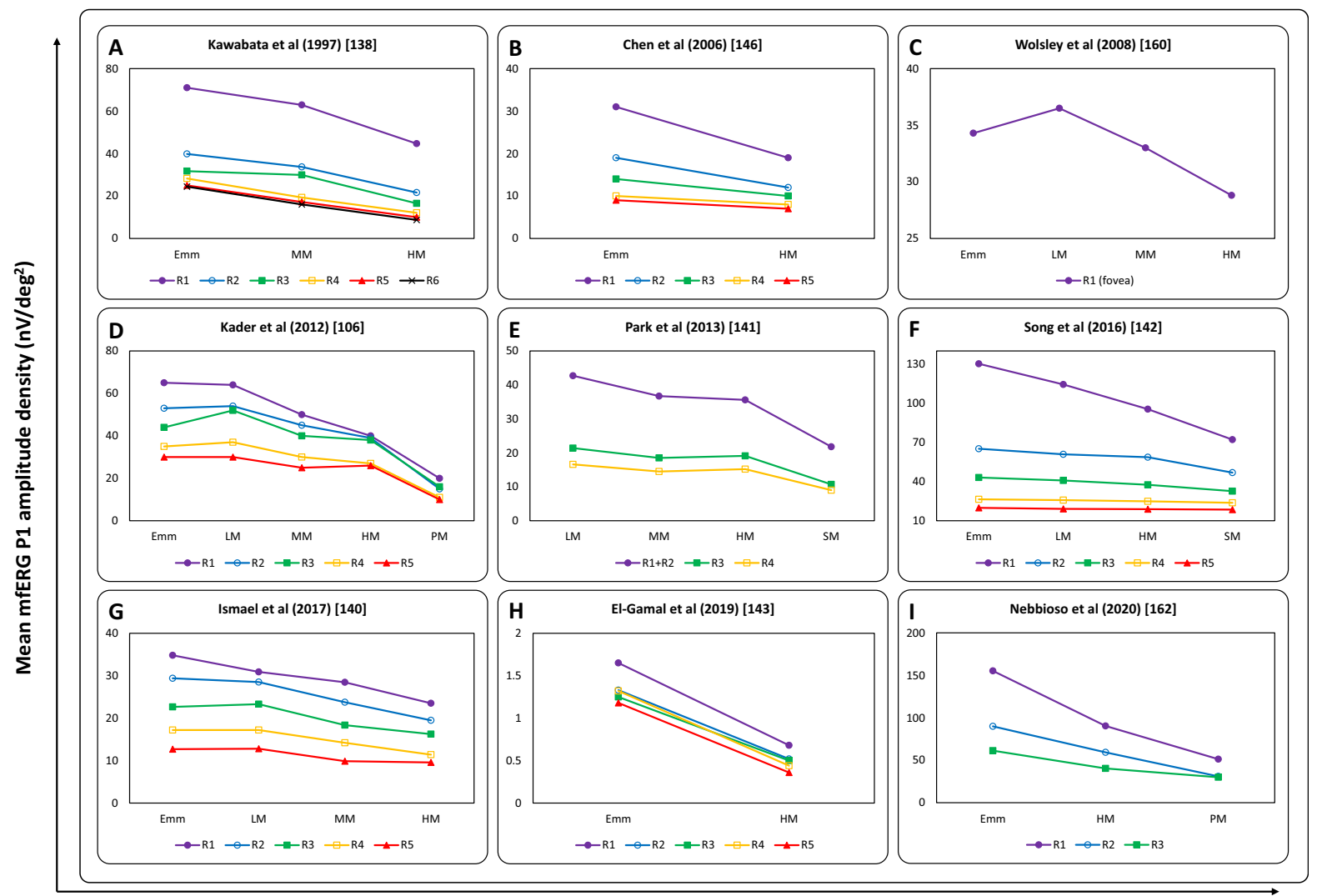

Refractive group

Fig. 4 Mean mfERG P1 amplitude density $\left(n V / d^{2}{ }^{2}\right)$ at each ring (R1: filled purple circles, R2: unfilled blue circles, R3: filled green squares, R4: unfilled orange squares, R5: filled red triangles, and R6: black cross) reported by each study in

P1 amplitude density, and delayed latency in the retinal periphery [160]. Significant correlations were observed between MIR thickness and N1, P1 amplitude density, as well as N1, P1 implicit time in the perifoveal retina corresponding to R4 [141]. However, no such significance was noted between central R1 parameters and central macular thickness [135]. The P1 amplitude density was also significantly correlated with the mean RNFL and outer macular thickness in R2, R4, R5, and R2 to R5, respectively [110].

Previous studies have shown an increase in the central subfield macular thickness (CST) [142] and a reduction in neural retinal thickness [144] with an increasing degree of myopia. The changes in CST were negatively associated with P1 amplitude [142, 162], P1 amplitude density [142], and microperimetry (MP-1) sensitivity [162]. In addition, the P1 amplitude density was found to decrease in all emmetropia (Emm) and various grades of myopia (LM: low myopia, MM: moderate myopia, HM: high myopia, SM: severe myopia, and PM: pathological myopia)

quadrants and rings with an increasing axial length [144]. The increase in CST in high myopes also led to an increase in P1 implicit time [142]. This shows that retinal morphological changes are closely associated with the retinal functional changes in high myopia [142, 144, 162]. Hence, the correlation between structural and functional changes is crucial for interpreting retinal health in myopes, especially in high myopia [142, 144, 161, 162].

\section{Pattern electroretinogram (PERG) and its responses in myopia}

The PERG is a contrast-based response, driven by macular photoreceptors and originating from retinal ganglion cells [94]. It is a measure of both central retinal function and retinal ganglion cell function 
[163]. In macaque monkeys, both $\mathrm{ON}$ and $\mathrm{OFF}$ pathways equally contribute to the transient PERG amplitudes [164]. Clinically, transient PERG response has two main components: P50 (positive peak at $50 \mathrm{~ms}$ from stimulus onset) is an inner retinal component driven by macular photoreceptors and N95 (negative peak at $95 \mathrm{~ms}$ from stimulus onset) is the second component which is contrast-related and is generated by the retinal ganglion cells [96].

The P50 and N95 wave amplitudes of the transient PERG response were reduced in high myopes with longer axial length compared to that of emmetropes and low myopes [101, 165-167]. The amount of loss in P50 amplitude was proportional to the degree of myopia, i.e., $8 \%$ in low myopes $(-1.00$ to $-3.00 \mathrm{D})$, $16 \%$ in moderate myopes $(-3.25$ to $-6.00 \mathrm{D})$, and $36 \%$ in high myopes $(-6.25$ to $-10.00 \mathrm{D})$, when compared with emmetropes or myopes up to -0.75 D [166]. Similarly, the amount of loss in N95 amplitude was also proportional to the degree of myopia, i.e., $7 \%$ in low myopes, $21 \%$ in moderate myopes, and $43 \%$ in high myopes, when compared with emmetropes [166]. Although P50 wave latencies show no difference, N95 wave latencies were reported to significantly increase in high myopia [166]. The reduced P50 and N95 amplitudes in higher degrees of myopia may indicate early macular and ganglion cell dysfunction even in eyes with normal vision and a healthy appearance of the macula [165-167].

\section{Global-flash multifocal electroretinogram (gmfERG) and its responses in myopia}

A further refinement of mfERG is the gmfERG, in which a successive insertion of a full-field or globalflash stimulus between consecutive focal flashes of a standard mfERG stimulus enhances the adaptive response, isolating the outer and inner retinal responses into two major components [168, 169]. The direct component (DC) is predominantly derived from the outer retinal cells (photoreceptors and bipolar cells), whereas the induced component (IC) is derived from the inner retinal cells (ganglion and amacrine cells) $[168,170-172]$.

The results from several studies that investigated gmfERG in myopia are given in Table 3. Evaluation of neural response from outer to inner retina in emmetropes and myopes using the gmfERG showed that both the DC and IC responses gradually decreased from R1 to R5. The IC responses were more affected as compared to the DC responses, indicating that the inner retina was greatly affected in myopes [173]. Both the DC and IC amplitude densities were significantly correlated for retinal mid-peripheral regions corresponding to R2 to R3 in myopic refractive error [173]. It is hypothesized that these gmfERG responses are mediated by light-adapted changes in the retinal dopaminergic system.

The gmfERG on myopic children with different contrast levels exhibited a significant reduction in central macular (R1) DC amplitude density at $96 \%$ contrast, while the IC amplitude density was unaffected [174]. But myopic adults showed a significant reduction in the paracentral DC amplitude density for $29 \%$ and $49 \%$ contrasts [175]. The IC amplitude density in myopic adults is reduced for all measured contrast levels in both central and peripheral retinas [175]. There were no significant changes for both DC and IC implicit times in children and adults [174, 175]. Overall, these findings suggest that gmfERG-derived inner and outer retinal function in myopes vary significantly with age and retinal eccentricity.

A similar contrast-based gmfERG setup was used to determine whether myopia progression measured over 1 year was associated with changes in retinal function. At $49 \%$ contrast, both the DC and IC amplitude densities at the macula (central R1) were significantly reduced with the progression of myopia [176-178]. The DC and IC implicit times were also reduced considerably in the paracentral retinal region [176, 177]. However, the high-contrast responses remained unaffected by the myopia progression [176-178]. The findings indicate that myopia progression in children alters the inner retinal function at central retina, along with partial involvement of paracentral retina $[176,177]$. The retinal electrophysiological functions seem not only differentially affected in children and adult myopes, but also in outer and inner retina that differentially process the spatial details [179].

\section{Electroretinogram responses to anti-myopia strategies}

Given an alarming rise in the prevalence of myopia worldwide, various optical, pharmacological, and 
Table 3 Summary of studies on global-flash mfERG (gmfERG) and myopia

\begin{tabular}{|c|c|c|}
\hline References & Participants & Outcomes \\
\hline $\begin{array}{l}\text { Chen et al. } \\
\text { [173] }\end{array}$ & $\begin{array}{l}10 \text { emmetropes }( \pm 0.75 \mathrm{D}) \text { and } 14 \text { myopes } \\
(<-0.75 \mathrm{D})\end{array}$ & $\begin{array}{l}\text { Increased DC, IC amplitudes in the paracentral retina (R2 to } \\
\mathrm{R} 3 \text { ) with increased degree of myopia }\end{array}$ \\
\hline $\begin{array}{l}\text { Ho et al. } \\
{[175]}\end{array}$ & 54 myopes (SER: 0.00 to $-8.13 \mathrm{D}$ ) & $\begin{array}{l}\text { Reduced paracentral DC amplitude for the } 29 \% \text { and } 49 \% \\
\text { contrasts in myopes. Reduced paracentral and peripheral IC } \\
\text { amplitudes at all contrasts measured and for the } 49 \% \text { contrast, } \\
\text { respectively, in myopes. SER contributed to about } 14 \% \text { and } \\
16 \% \text { of the variance in DC and IC amplitude, respectively }\end{array}$ \\
\hline $\begin{array}{l}\text { Ho et al. } \\
\text { [177] }\end{array}$ & 22 myopic children (mean age: $11 \pm 1$ years) & $\begin{array}{l}\text { Delayed DC (R3) and IC (R2 to R5) IT at } 49 \% \text { contrast in } \\
\text { children with myopia progression. Delayed IC IT (R1) at } 96 \% \\
\text { contrast in children with myopia progression }\end{array}$ \\
\hline $\begin{array}{l}\text { Ho et al. } \\
\text { [176] }\end{array}$ & $\begin{array}{l}26 \text { myopic children (9-13 years) with varying } \\
\text { degrees of myopia }\end{array}$ & $\begin{array}{l}\text { Reduced central DC, IC amplitudes, and paracentral IT at } 49 \% \\
\text { contrast in children with myopia progression }\end{array}$ \\
\hline $\begin{array}{l}\text { Ho et al. } \\
{[174]}\end{array}$ & $\begin{array}{l}52 \text { children }(9-14 \text { years }) \text { and } 19 \text { young adults } \\
(21-28 \text { years }) \text { with SER ranging from } 0.00 \\
\text { to }-5.50 \mathrm{D}\end{array}$ & $\begin{array}{l}\text { Reduced central DC amplitude at } 96 \% \text { contrast in myopic } \\
\text { children. Reduced paracentral IC amplitude at } 49 \% \text { contrast } \\
\text { in myopic adults }\end{array}$ \\
\hline $\begin{array}{l}\text { Chin et al. } \\
\text { [179] }\end{array}$ & 23 emmetropes to low myopes $(+1.00$ to $-3.25 \mathrm{D})$ & $\begin{array}{l}\text { Reduced DC amplitude at a low SF, which increased with } \\
\text { increasing SF, and decreased with increasing eccentricity }\end{array}$ \\
\hline \multicolumn{3}{|c|}{ Increased IC amplitude at all SF, which decreased with increasing eccentricity } \\
\hline $\begin{array}{l}\text { Li et al. } \\
\text { [178] }\end{array}$ & 56 emmetropic children $( \pm 0.50 \mathrm{D})$ & $\begin{array}{l}\text { Reduced central IC amplitudes at } 49 \% \text { contrast with the myopic } \\
\text { changes in SER and AL after } 1 \text { year }\end{array}$ \\
\hline
\end{tabular}

$A L$ axial length, $D C$ direct component, $E R G$ electroretinogram, gmfERG global-flash multi-focal electroretinogram, $I C$ induced component, $I T$ implicit time, $R 1-R 5$ ring 1 to ring 5 from center to periphery, $S E R$ spherical equivalent refractive error, $S F$ spatial frequency

environmental strategies are being incorporated to prevent the development of myopia [180] as well as to slow down the rate of myopia progression in children $[181,182]$. One of the popular optical anti-myopia strategies includes orthokeratology [183, 184], which decreases the hyperopic defocus at the peripheral retina in myopic eyes [185-187]. A recent investigation on the effect of 60 days of orthokeratology treatment on PERG reported significantly delayed implicit time of P50 and N95 wave, but no effect on PERG amplitudes [188]. Because the blur induced by orthokeratology and other peripheral defocus inducing anti-myopia strategies is not the same across all retinal eccentricities, it would be useful to use the mfERG to investigate how ERG responses vary in different retinal regions.

Besides optical anti-myopia strategies, pharmacological management of myopia progression with atropine eye drops has also been one of the most effective strategies to control myopia progression in children [181, 189-193]. The majority of previous ERG studies that investigated different concentrations of atropine eye drops $(0.01 \%, 0.1 \%, 0.5 \%$, and $1 \%)$ on retinal signals reported no significant effect of atropine on retinal function as demonstrated by ffERG [194-196], mfERG [194, 197], or PERG [198] in young myopic children $(<14$ years of age). However, there are a few studies that report contradictory results. Firstly, Khanal et al. [199] reported that $0.1 \%$ atropine eye drops resulted in a $14 \%$ reduction of dark-adapted 3.0 OP amplitudes and $4 \%$ delay in the a-wave implicit time of dark-adapted 10.0 ERG (stronger ffERG), indicating that atropine could alter neural activity in inner retina and activity of photoreceptors, respectively [199]. Secondly, Kothari et al. [194] reported a reduction in the P50 amplitude of PERG with $0.01 \%$ atropine eye drops, indicating that the induced optical blur due to cycloplegia and mydriasis may alter signal transmission in inner retina (amacrine cells) [194]. Lastly, it was reported that gmfERG responses increased with $0.1 \%$ atropine eye drops in the presence of optically induced myopic defocus, suggesting that the atropine may enhance the effects of myopic defocus in the inner layers of the peripheral retina in controlling the eye growth for potential anti-myopia effects [200]. Overall, the literature related to the influence of atropine eye drops on altering retinal signals and regulating ocular growth is sparse and 
warrants further in-depth investigations to improve understanding of this important relationship and mechanism.

\section{Conclusions}

To summarize, there are significant changes in retinal function, as assessed from ERG testing in myopes, and these changes strongly correlate with axial length and the degree of myopia. Although some investigations with the ffERG show significantly reduced darkadapted and light-adapted a- and b-wave amplitudes with increasing degree of myopic refractive error, there is some evidence that dark-adapted responses are further attenuated than the light-adapted responses. These findings suggest that myopia may be associated with reduced photoreceptor (mainly rod response) and ON-bipolar cell activity. Several studies with the mfERG show reduced P1 amplitude density in myopes, suggesting alterations in retinal $\mathrm{ON}$-andOFF cone bipolar cells in myopia. The mfERG amplitude density associated with refractive error varies significantly with retinal eccentricity (larger reduction in peripheral retina than in the fovea), axial length, and the degree of myopia. Finally, studies have reported reduced PERG amplitudes and gmfERG amplitude density in both the central and paracentral retina in high myopia. While these studies illustrate important associations between myopic refractive error and changes in retinal electrical activity, there has been limited work to understand the longitudinal changes in the ERG and how they relate to myopia progression in younger eyes. Future work investigating electrophysiological responses in combination with the measurements of retinal structural changes (using optical coherence tomography) will provide valuable insights into how retinal electrical changes may influence ocular growth and refractive error development in humans. Given the availability and wide use of optical and pharmacological anti-myopia management strategies that are known to act at retinal level (such as orthokeratology, multifocal contact lenses, and atropine), it would also be interesting for future studies to examine how these anti-myopia interventions interact with retinal signals to prevent myopia.
Authors' contributions All authors contributed to the study's conception and design. Material preparation, literature search, and data analysis were performed by SKG. The first draft of the manuscript was written by SKG, and all authors commented on previous versions of the manuscript. PKV and RC supervised and critically revised the work. All authors read and approved the final manuscript.

Funding This research was supported by the partnership grant between the L V Prasad Eye Institute and the Department of Biotechnology, Government of India (BT/PR32404/MED/30/ 2136/2019) and by the Hyderabad Eye Research Foundation, L V Prasad Eye Institute.

\section{Declarations}

Conflicts of interest The authors declare that they have no conflict of interest.

Ethical approval No prior ethics approval was required in this research.

Human and animal rights No human participants were used in this research. No animals were used in this research.

Open Access This article is licensed under a Creative Commons Attribution 4.0 International License, which permits use, sharing, adaptation, distribution and reproduction in any medium or format, as long as you give appropriate credit to the original author(s) and the source, provide a link to the Creative Commons licence, and indicate if changes were made. The images or other third party material in this article are included in the article's Creative Commons licence, unless indicated otherwise in a credit line to the material. If material is not included in the article's Creative Commons licence and your intended use is not permitted by statutory regulation or exceeds the permitted use, you will need to obtain permission directly from the copyright holder. To view a copy of this licence, visit http://creativecommons.org/licenses/by/4.0/.

\section{References}

1. Dolgin E (2015) The myopia boom. Nature 519:276-278

2. Holden BA, Fricke TR, Wilson DA et al (2016) Global prevalence of myopia and high myopia and temporal trends from 2000 through 2050. Ophthalmology 123:1036-1042

3. Holden BA, Jong M, Davis S et al (2015) Nearly 1 billion myopes at risk of myopia-related sight-threatening conditions by 2050 - time to act now. Clin Exp Optom 98:491-493

4. Flitcroft DI (2012) The complex interactions of retinal, optical and environmental factors in myopia aetiology. Prog Retin Eye Res 31:622-660

5. Morgan IG, Ohno-Matsui K, Saw SM (2012) Myopia. Lancet (London, England) 379:1739-1748 
6. Morgan IG, French AN, Ashby RS et al (2018) The epidemics of myopia: aetiology and prevention. Prog Retin Eye Res 62:134-149

7. Rudnicka AR, Kapetanakis VV, Wathern AK et al (2016) Global variations and time trends in the prevalence of childhood myopia, a systematic review and quantitative meta-analysis: implications for aetiology and early prevention. Br J Ophthalmol 100:882-890

8. Williams KM, Bertelsen G, Cumberland P et al (2015) Increasing Prevalence of Myopia in Europe and the Impact of Education. Ophthalmology 122:1489-1497

9. Priscilla JJ, Verkicharla PK (2021) Time trends on the prevalence of myopia in India - A prediction model for 2050. Ophthalmic Physiol Opt 41:466-474

10. Pan CW, Ramamurthy D, Saw SM (2012) Worldwide prevalence and risk factors for myopia. Ophthalmic Physiol Opt 32:3-16

11. Saw SM, Gazzard G, Shih-Yen EC et al (2005) Myopia and associated pathological complications. Ophthalmic Physiol Opt 25:381-391

12. Spaide RF, Ohno-Matsui K, Yannuzzi LA (2014) Pathologic myopia, 1st edn. Springer, New York

13. Dhakal R, Goud A, Narayanan R et al (2018) Patterns of posterior ocular complications in myopic eyes of Indian population. Sci Rep 8:13700

14. Wong YL, Ding Y, Sabanayagam C et al (2018) Longitudinal changes in disc and retinal lesions among highly myopic adolescents in Singapore Over a 10-Year period. Eye Contact Lens 44:286-291

15. Krebs W, Krebs I (1991) Embryology of Retina and Choroid. Primate Retina and Choroid. Springer, New York

16. Remington LA (2012) Ocular embryology. Clinical anatomy and physiology of the visual system, 3 edn. Elsevier: Butterworth-Heinemann, St. Louis, Missouri, pp 123-143

17. Hendrickson A (2016) Development of retinal layers in prenatal human retina. Am J Ophthalmol 161:29-35

18. Provis JM, van Driel D, Billson FA et al (1985) Development of the human retina: patterns of cell distribution and redistribution in the ganglion cell layer. J Comp Neurol 233:429-451

19. Crewther DP (2000) The role of photoreceptors in the control of refractive state. Prog Retin Eye Res 19:421-457

20. Chakraborty R, Pardue MT (2015) Molecular and biochemical aspects of the retina on refraction. In: Hejtmancik JF, Nickerson JM (eds) Progress in molecular biology and translational science. Academic Press, Burlington, pp 249-267

21. Masland RH (2001) Neuronal diversity in the retina. Curr Opin Neurobiol 11:431-436

22. Jeon C-J, Strettoi E, Masland RH (1998) The major cell populations of the mouse retina. J Neurosci 18:8936-8946

23. Masland Richard H (2012) The neuronal organization of the retina. Neuron 76:266-280

24. Hoon M, Okawa H, Della Santina L et al (2014) Functional architecture of the retina: development and disease. Prog Retin Eye Res 42:44-84

25. Masland RH (2001) The fundamental plan of the retina. Nat Neurosci 4:877-886

26. Purves D, Augustine GJ, Fitzpatrick D et al (2004) Vision: the eye. In: Purves D, Augustine GJ, Fitzpatrick D et al (eds) Neuroscience, 3rd edn. Sinauer Associates Inc, Sunderland, Massachusetts (USA), pp 229-257

27. Remington LA (2012) Retina. Clinical anatomy and physiology of the Visual System, 3rd edn. Elsevier: Butterworth-Heinemann, St. Louis, Missouri, pp 61-92

28. Hart NS (2009) Phototransduction. In: Binder MD, Hirokawa N, Windhorst U (eds) Encyclopedia of Neuroscience. Springer, Berlin, Heidelberg, pp 3156-3159

29. McBrien NA, Moghaddam HO, Cottriall CL et al (1995) The effects of blockade of retinal cell action potentials on ocular growth, emmetropization and form deprivation myopia in young chicks. Vision Res 35:1141-1152

30. Fischer AJ, Miethke P, Morgan IG et al (1998) Cholinergic amacrine cells are not required for the progression and atropine-mediated suppression of form-deprivation myopia. Brain Res 794:48-60

31. Schwahn HN, Schaeffel F (1994) Chick eyes under cycloplegia compensate for spectacle lenses despite sixhydroxy dopamine treatment. Invest Ophthalmol Vis Sci 35:3516-3524

32. Ehrlich D, Sattayasai J, Zappia J et al (2007) Effects of selective neurotoxins on eye growth in the young chick. In: Bock GR, Widdows K (eds) Ciba foundation symposium 155 - Myopia and the Control of Eye Growth, 1st edn. Wiley, New york

33. Norton TT, Essinger JA, McBrien NA (1994) Lid-suture myopia in tree shrews with retinal ganglion cell blockade. Vis Neurosci 11:143-153

34. Wildsoet CF, Pettigrew JD (1988) Kainic acid-induced eye enlargement in chickens: differential effects on anterior and posterior segments. Invest Ophthalmol Vis Sci 29:311-319

35. Irving EL, Callender MG, Sivak JG (1991) Inducing myopia, hyperopia, and astigmatism in chicks. Optom Vis Sci 68:364-368

36. Irving EL, Sivak JG, Callender MG (1992) Refractive plasticity of the developing chick eye. Ophthalmic Physiol Opt 12:448-456

37. Nickla DL, Wildsoet C, Wallman J (1998) Visual influences on diurnal rhythms in ocular length and choroidal thickness in chick eyes. Exp Eye Res 66:163-181

38. Schaeffel F, Glasser A, Howland HC (1988) Accommodation, refractive error and eye growth in chickens. Vision Res 28:639-657

39. Schmid KL, Wildsoet CF (1996) Effects on the compensatory responses to positive and negative lenses of intermittent lens wear and ciliary nerve section in chicks. Vision Res 36:1023-1036

40. Wallman J, Wildsoet C, Xu A et al (1995) Moving the retina: choroidal modulation of refractive state. Vision Res 35:37-50

41. Wildsoet C, Wallman J (1995) Choroidal and scleral mechanisms of compensation for spectacle lenses in chicks. Vision Res 35:1175-1194

42. Schaeffel F, Troilo D, Wallman J et al (1990) Developing eyes that lack accommodation grow to compensate for imposed defocus. Vis Neurosci 4:177-183

43. Schippert R, Schaeffel F (2006) Peripheral defocus does not necessarily affect central refractive development. Vision Res 46:3935-3940 
44. Crewther DP, Crewther SG (2002) Refractive compensation to optical defocus depends on the temporal profile of luminance modulation of the environment. Neuro Report 13:1029-1032

45. Turnbull PRK, Backhouse S, Phillips JR (2015) Visually guided eye growth in the squid. Curr Biol 25:R791-R792

46. Norton TT, Siegwart JT Jr, Amedo AO (2006) Effectiveness of hyperopic defocus, minimal defocus, or myopic defocus in competition with a myopiagenic stimulus in tree shrew eyes. Invest Ophthalmol Vis Sci 47:4687-4699

47. Hung L-F, Crawford MLJ, Smith EL (1995) Spectacle lenses alter eye growth and the refractive status of young monkeys. Nat Med 1:761-765

48. Smith EL, Huang J, Hung LF et al (2009) Hemiretinal form deprivation: evidence for local control of eye growth and refractive development in infant monkeys. Invest Ophthalmol Vis Sci 50:5057-5069

49. Smith EL, Hung L-F (1999) The role of optical defocus in regulating refractive development in infant monkeys. Vision Res 39:1415-1435

50. Smith EL, Hung LF, Huang J et al (2013) Effects of local myopic defocus on refractive development in monkeys. Optom Vis Sci 90:1176-1186

51. Smith EL, Hung LF, Huang J et al (2010) Effects of optical defocus on refractive development in monkeys: evidence for local, regionally selective mechanisms. Invest Ophthalmol Vis Sci 51:3864-3873

52. Smith EL, Ramamirtham R, Qiao-Grider Y et al (2007) Effects of foveal ablation on emmetropization and formdeprivation myopia. Invest Ophthalmol Vis Sci 48:3914-3922

53. Smith EL, Kee CS, Ramamirtham R et al (2005) Peripheral vision can influence eye growth and refractive development in infant monkeys. Invest Ophthalmol Vis Sci 46:3965-3972

54. Smith EL, Hung LF, Huang J (2009) Relative peripheral hyperopic defocus alters central refractive development in infant monkeys. Vision Res 49:2386-2392

55. Smith EL, Hung LF, Arumugam B (2014) Visual regulation of refractive development: insights from animal studies. Eye 28:180-188

56. Graham B, Judge SJ (1999) The effects of spectacle wear in infancy on eye growth and refractive error in the marmoset (Callithrix jacchus). Vision Res 39:189-206

57. Howlett MHC, McFadden SA (2009) Spectacle lens compensation in the pigmented guinea pig. Vision Res 49:219-227

58. Nathan J, Crewther SG, Crewther DP et al (1984) Effects of retinal image degradation on ocular growth in cats. Invest Ophthalmol Vis Sci 25:1300-1306

59. Smith EL, Maguire GW, Watson JT (1980) Axial lengths and refractive errors in kittens reared with an optically induced anisometropia. Invest Ophthalmol Vis Sci 19:1250-1255

60. Smith EL, Fox DA, Duncan GC (1991) Refractive-error changes in kitten eyes produced by chronic on-channel blockade. Vision Res 31:833-844

61. Barathi VA, Boopathi VG, Yap EPH et al (2008) Two models of experimental myopia in the mouse. Vision Res 48:904-916
62. Tkatchenko TV, Shen Y, Tkatchenko AV (2010) Mouse experimental myopia has features of primate myopia. Invest Ophthalmol Vis Sci 51:1297-1303

63. Park H, Jabbar SB, Tan CC et al (2014) Visually-driven ocular growth in mice requires functional rod photoreceptors. Invest Ophthalmol Vis Sci 55:6272-6279

64. Chakraborty R, Read SA, Collins MJ (2012) Monocular myopic defocus and daily changes in axial length and choroidal thickness of human eyes. Exp Eye Res 103:47-54

65. Chakraborty R, Read SA, Collins MJ (2013) Hyperopic defocus and diurnal changes in human choroid and axial length. Optom Vis Sci 90:1187-1198

66. Moderiano D, Do M, Hobbs S et al (2019) Influence of the time of day on axial length and choroidal thickness changes to hyperopic and myopic defocus in human eyes. Exp Eye Res 182:125-136

67. Wang D, Chun RK, Liu M et al (2016) Optical defocus rapidly changes choroidal thickness in school children. PLoS ONE 11:e0161535

68. Phillips JR (2005) Monovision slows juvenile myopia progression unilaterally. Br J Ophthalmol 89:1196-1200

69. Wallman J, Winawer J (2004) Homeostasis of eye growth and the question of myopia. Neuron 43:447-468

70. Chakraborty R, Ostrin LA, Benavente-Perez A et al (2020) Optical mechanisms regulating emmetropisation and refractive errors: evidence from animal models. Clin Exp Optom 103:55-67

71. Charman WN, Radhakrishnan H (2010) Peripheral refraction and the development of refractive error: a review. Ophthalmic Physiol Opt 30:321-338

72. Norton TT (1999) Animal models of myopia: learning how vision controls the size of the eye. ILAR J 40:59-77

73. Troilo D, Smith EL III, Nickla DL et al (2019) IMI Report on experimental models of emmetropization and myopia. Invest Ophthalmol Vis Sci 60:M31-M88

74. Harper AR, Summers JA (2015) The dynamic sclera: extracellular matrix remodeling in normal ocular growth and myopia development. Exp Eye Res 133:100-111

75. Choh V, Lew MY, Nadel MW et al (2006) Effects of interchanging hyperopic defocus and form deprivation stimuli in normal and optic nerve-sectioned chicks. Vision Res 46:1070-1079

76. Chung KM (1993) Critical review: effects of optical defocus on refractive development and ocular growth and relation to accommodation. Optom Vis Sci 70:228-233

77. Nevin ST, Schmid KL, Wildsoet CF (1998) Sharp vision: a prerequisite for compensation to myopic defocus in the chick? Curr Eye Res 17:322-331

78. Lauber JK, Kinnear A (1979) Eye enlargement in birds induced by dim light. Can J Ophthalmol 14:265-269

79. Chakraborty R, Read SA, Vincent SJ (2020) Understanding myopia: pathogenesis and mechanisms. In: Ang M, Wong TY (eds) Updates on myopia: a clinical perspective. Springer, Singapore

80. Westbrook AM, Crewther SG, Beresford JA et al (1995) Formoguanamine-induced inhibition of deprivation myopia in chick is accompanied by choroidal thinning while retinal function is retained. Vision Res 35:2075-2088 
81. Crewther DP, Crewther SG (1990) Pharmacological modification of eye growth in normally reared and visually deprived chicks. Curr Eye Res 9:733-740

82. Crewther DP, Crewther SG, Xie RZ (1996) Changes in eye growth produced by drugs which affect retinal $\mathrm{ON}$ or $\mathrm{OFF}$ responses to light. J Ocul Pharmacol Ther 12:193-208

83. Crewther SG, Crewther DP (2003) Inhibition of retinal ON/OFF systems differentially affects refractive compensation to defocus. NeuroReport 14:1233-1237

84. Chakraborty R, Park H, Aung MH et al (2014) Comparison of refractive development and retinal dopamine in OFF pathway mutant and C57BL/6J wild-type mice. Mol Vis 20:1318-1327

85. Chakraborty R, Hn P, Hanif AM et al (2015) ON pathway mutations increase susceptibility to form-deprivation myopia. Exp Eye Res 137:79-83

86. Pardue MT, Faulkner AE, Fernandes A et al (2008) High susceptibility to experimental myopia in a mouse model with a retinal on pathway defect. Invest Ophthalmol Vis Sci 49:706-712

87. Pardue MT, Stone RA, Iuvone PM (2013) Investigating mechanisms of myopia in mice. Exp Eye Res 114:96-105

88. Pan F (2019) Defocused image changes signaling of ganglion cells in the mouse retina. Cells 8:640

89. Fain G, Sampath AP (2018) Rod and cone interactions in the retina. F1000Res 7:1-9

90. Morgan IG (2003) The biological basis of myopic refractive error. Clin Exp Optom 86:276-288

91. Joselevitch C (2008) Human retinal circuitry and physiology. Psychol Neurosci 1:141-165

92. Mahabadi N, Al-Khalili Y (2020) Neuroanatomy Retina. StatPearls Publishing, Treasure Island (FL)

93. Quinn N, Csincsik L, Flynn E et al (2019) The clinical relevance of visualising the peripheral retina. Prog Retin Eye Res 68:83-109

94. Robson AG, Nilsson J, Li S et al (2018) ISCEV guide to visual electrodiagnostic procedures. Doc Ophthalmol 136:1-26

95. Hoffmann MB, Bach M, Kondo M et al (2021) ISCEV standard for clinical multifocal electroretinography (mfERG) (2021 update). Doc Ophthalmol 142:5-16

96. Bach M, Brigell MG, Hawlina M et al (2013) ISCEV standard for clinical pattern electroretinography (PERG): 2012 update. Doc Ophthalmol 126:1-7

97. McCulloch DL, Marmor MF, Brigell MG et al (2015) ISCEV Standard for full-field clinical electroretinography (2015 update). Doc Ophthalmol 130:1-12

98. Frishman LJ (2006) Origins of the electroretinogram. In: Heckenlively JR, Arden GB (eds) Principles and practice of clinical electrophysiology of vision, 2 nd edn. The MIT Press, Cambridge, MA, pp 139-183

99. Jalali S, Mohan Ram L, Tyagi G et al (2009) Electrophysiological tests for visual function assessment. In: Nema H, Nema N (eds) Diagnostic procedures in ophthalmology, 2nd edn. Jaypee Brothers Medical Publishers Pvt. Ltd., New Delhi, India, pp 279-315

100. Perlman I (2020) The Electroretinogram: ERG. In: Kolb H, Fernandez E, Nelson R (eds) Webvision: the organization of the retina and visual system. University of Utah Health Sciences Center, Salt Lake City (UT), pp 1371-1412
101. Flitcroft DI, Adams GG, Robson AG et al (2005) Retinal dysfunction and refractive errors: an electrophysiological study of children. Br J Ophthalmol 89:484-488

102. Steinberg RH, Schmidt R, Brown KT (1970) Intracellular responses to light from cat pigment epithelium: origin of the electroretinogram c-Wave. Nature 227:728-730

103. Brown KT (1968) The electroretinogram: its components and their origins. Vision Res 8:633-677

104. Sieving PA, Murayama K, Naarendorp F (1994) Push-pull model of the primate photopic electroretinogram: a role for hyperpolarizing neurons in shaping the b-wave. Vis Neurosci 11:519-532

105. Karpe G (1945) The basis of clinical electroretinography. Acta Ophthalmol 1-118

106. Kader MA (2012) Electrophysiological study of myopia. Saudi J Ophthalmol 26:91-99

107. Perlman I, Meyer E, Haim T et al (1984) Retinal function in high refractive error assessed electroretinographically. Br J Ophthalmol 68:79-84

108. Westall CA, Dhaliwal HS, Panton CM et al (2001) Values of electroretinogram responses according to axial length. Doc Ophthalmol 102:115-130

109. Sachidanandam R, Ravi P, Sen P (2017) Effect of axial length on full-field and multifocal electroretinograms. Clin Exp Optom 100:668-675

110. Koh V, Tan C, Nah G et al (2014) Correlation of structural and electrophysiological changes in the retina of young high myopes. Ophthalmic Physiol Opt 34:658-666

111. Shamshinova AM, Tarutta EP, Zol'nikova IV et al (2008) Retinal bioelectrical activity in children with congenital myopia. Vestn Oftalmol 124:44-50

112. Malik SRK, Gupta A, Gupta P et al (1969) E R G in myopia. Indian J Ophthalmol 17:48-51

113. Yoshii M, Yanashima K, Nagasaka E et al (2002) Nonlinear Component of the Electroretinogram Recorded from the Posterior Pole of Normal and Highly Myopic Human Eyes. Ophthalmic Res 34:393-399

114. Kawabata H, Adachi-Usami E (1997) Electrophysiological changes of photopic function in myopia. In: Tokora $\mathrm{T}$ (ed) Proceeding of the sixth international conference on myopia, Hakone, 1996; Myopia update. Springer-Verlag, Tokyo, pp 388-393

115. Prijot E, Colmant I, Marechal-Courtois C (1968) Electroretinography and myopia. In: Francois J (ed) Proceeding of the Fifth International Society Clinical Electrophysiology of Vision Symposium, Ghent, 1966; The Clinical Value of Electroretinography. Karger, Basel, pp 440-443

116. Yamamoto S, Nitta K, Kamiyama M (1997) Cone electroretinogram to chromatic stimuli in myopic eyes. Vision Res 37:2157-2159

117. Wang P, Xiao X, Huang L et al (2013) Cone-rod dysfunction is a sign of early-onset high myopia. Optom Vis Sci 90:1327-1330

118. Jayle G (1960) Les donnees de l'electroretinographie "dynamique" dans la myopie. Acta Fae Med Univ Brunensis 4:263

119. Blach RK, Jay B, Kolb H (1966) Electrical activity of the eye in high myopia. Brit J Ophthal 50:629-641 
120. Ishikawa M, Miyake Y, Shiroyama N (1990) Focal macular electroretinogram in high myopia. Nippon Ganka Gakkai Zasshi 94:1040-1047

121. Ohno-Matsui K, Wu P-C, Yamashiro K et al (2021) IMI Pathologic Myopia. Invest Ophthalmol Vis Sci 62:5

122. Wan W, Chen Z, Lei B (2020) Increase in electroretinogram rod-driven peak frequency of oscillatory potentials and dark-adapted responses in a cohort of myopia patients. Doc Ophthalmol 140:189-199

123. Lei B, Yao G, Zhang K et al (2006) Study of rod- and conedriven oscillatory potentials in mice. Invest Ophthalmol Vis Sci 47:2732-2738

124. Yin JP, Lei B, Peng H et al (2011) Characteristics of darkadapted and light-adapted oscillatory potentials in human electroretinogram. Nan Fang Yi Ke Da Xue Xue Bao 31:2057-2060

125. Zhang K, Yao G, Gao Y et al (2007) Frequency spectrum and amplitude analysis of dark- and light-adapted oscillatory potentials in albino mouse, rat and rabbit. Doc Ophthalmol 115:85-93

126. Fujikado T, Kawasaki Y, Suzuki A et al (1997) Retinal function with lens-induced myopia compared with formdeprivation myopia in chicks. Graefes Arch Clin Exp Ophthalmol 235:320-324

127. King-Smith PE, Loffing DH, Jones R (1986) Rod and cone ERGs and their oscillatory potentials. Invest Ophthalmol Vis Sci 27:270-273

128. Toda K, Bush RA, Humphries P et al (1999) The electroretinogram of the rhodopsin knockout mouse. Vis Neurosci 16:391-398

129. Schmid KL, Wildsoet CF (2004) Inhibitory effects of apomorphine and atropine and their combination on myopia in chicks. Optom Vis Sci 81:137-147

130. Fulton AB, Hansen RM (1996) Electroretinogram responses and refractive errors in patients with a history of retinopathy of prematurity. Doc Ophthalmol 91:87-100

131. Sutter EE, Tran D (1992) The field topography of ERG components in man-I. The photopic luminance response Vision Res 32:433-446

132. Lai TY, Chan WM, Lai RY et al (2007) The clinical applications of multifocal electroretinography: a systematic review. Surv Ophthalmol 52:61-96

133. Vilela C, Cortes V, Vallet M (1998) Electroretinogram: technique and clinical applications. Rev Neurol 26:444-447

134. Kretschmann U, Bock M, Gockeln R et al (2000) Clinical applications of multifocal electroretinography. Doc Ophthalmol 100:99-113

135. Azad R, Ghatak U, Sharma YR et al (2012) Multifocal electroretinogram in normal emmetropic subjects: correlation with optical coherence tomography. Indian J Ophthalmol 60:49-52

136. Hood DC, Frishman LJ, Saszik S et al (2002) Retinal origins of the primate multifocal ERG: implications for the human response. Invest Ophthalmol Vis Sci 43:1673-1685

137. Hood DC, Bach M, Brigell M et al (2012) ISCEV standard for clinical multifocal electroretinography (mfERG) (2011 edition). Doc Ophthalmol 124:1-13

138. Kawabata H, Adachi-Usami E (1997) Multifocal electroretinogram in myopia. Invest Ophthalmol Vis Sci $38: 2844-2851$
139. Luu CD, Lau AMI, Lee S-Y (2006) Multifocal electroretinogram in adults and children with myopia. Arch Ophthalmol 124:328-334

140. Ismael ZF, El-Shazly AAE-F, Farweez YA et al (2017) Relationship between functional and structural retinal changes in myopic eyes. Clin Exp Optom 100:695-703

141. Park S, Kim SH, Park TK et al (2013) Evaluation of structural and functional changes in non-pathologic myopic fundus using multifocal electroretinogram and optical coherence tomography. Doc Ophthalmol 126:199-210

142. Song AP, Yu T, Wang JR et al (2016) Multifocal electroretinogram in non-pathological myopic subjects: correlation with optical coherence tomography. Int $\mathbf{J}$ Ophthalmol 9:286-291

143. El-Gamal AA, Salama OH, Hassouna AA (2019) Multifocal electroretinogram changes in Egyptians with axial high myopia. Egypt J Hosp Med 74:524-533

144. Ying T, Wen-bin W, Dan Z et al (2008) Observation on morphology and function of macular in pathologic myopia. Chin J Ophthalmol 44:794-799

145. Chen JC, Brown B, Schmid KL (2006) Delayed mfERG responses in myopia. Vision Res 46:1221-1229

146. Chen JC, Brown B, Schmid KL (2006) Slow flash multifocal electroretinogram in myopia. Vision Res 46:2869-2876

147. Hood DC (2000) Assessing retinal function with the multifocal technique. Prog Retin Eye Res 19:607-646

148. Sun X, Jianjun L, Wang Y (1999) The effects of myopia on first-order kernels responses of multifocal electroretinogram. Chin J Ocul Fundus Dis 2:103-105

149. Luu CD, Foulds WS, Tan DTH (2007) Features of the multifocal electroretinogram may predict the rate of myopia progression in children. Ophthalmology 114:1433-1438

150. Chen JC, Brown B, Schmid KL (2006) Evaluation of inner retinal function in myopia using oscillatory potentials of the multifocal electroretinogram. Vision Res 46:4096-4103

151. Pallin O (1969) Influence of axial length of the eye on the size of the recorded b-potential in the clinical single-flash electroretinogram. Acta Ophthalmol 47(Suppl):1-57

152. Chen JF, Elsner A, Burns S et al (1992) The effect of eye shape on retinal responses. Clin Vis Sci 7:521-530

153. Curtin BJ, Karlin DB (1971) Axial length measurements and fundus changes of the myopic eye. Am J Ophthalmol 71:42-53

154. Karlin DB, Curtin BJ (1976) Peripheral chorioretinal lesions and axial length of the myopic eye. Am J Ophthalmol 81:625-635

155. Beresford JA, Crewther SG, Crewther DP (1998) Anatomical correlates of experimentally induced myopia. Aust New Zeal J Ophthalmol 26:S84-S87

156. Liang H, Crewther DP, Gillard Crewther S et al (1995) A role for photoreceptor outer segments in the induction of deprivation myopia. Vision Res 35:1217-1225

157. Copenhagen DR (2004) Excitation in the retina: the flow, filtering, and molecules of visual signaling in the glutamatergic pathways from photoreceptors to ganglion cells. In: Chalupa LM, Werner JS (eds) The visual neurosciences. The MIT Press, London, pp 320-333 
158. Chan HL, Mohidin N (2003) Variation of multifocal electroretinogram with axial length. Ophthalmic Physiol Opt 23:133-140

159. Cheng SC, Lam CS, Yap MK (2010) Retinal thickness in myopic and non-myopic eyes. Ophthalmic Physiol Opt 30:776-784

160. Wolsley CJ, Saunders KJ, Silvestri G et al (2008) Investigation of changes in the myopic retina using multifocal electroretinograms, optical coherence tomography and peripheral resolution acuity. Vision Res 48:1554-1561

161. Tarutta EP, Markosian GA, Riabina MV et al (2012) Morphometric and functional features of macula in patients with high congenital myopia. Vestn Oftalmol 128:3-8

162. Nebbioso M, Lambiase A, Gharbiya M et al (2020) High myopic patients with and without foveoschisis: morphological and functional characteristics. Doc Ophthalmol 141(3):227-236

163. Hull BM, Thompson DA (1989) A review of the clinical applications of the pattern electroretinogram. Ophthalmic Physiol Opt 9:143-152

164. Luo X, Frishman LJ (2011) Retinal pathway origins of the pattern electroretinogram (PERG). Invest Ophthalmol Vis Sci 52:8571-8584

165. Hidajat R, Mclay J, Burley C et al (2003) Influence of axial length of normal eyes on PERG. Doc Ophthalmol 107:195-200

166. Oner A, Gumus K, Arda H et al (2009) Pattern electroretinographic recordings in eyes with myopia. Eye Contact Lens 35:238-241

167. Lubiński W (1991) Electroretinogram of the "pattern" type of eyes with medium grade myopia. Klin Oczna 93:284-285

168. Shimada Y, Bearse MA Jr, Sutter EE (2005) Multifocal electroretinograms combined with periodic flashes: direct responses and induced components. Graefes Arch Clin Exp Ophthalmol 243:132-141

169. Sutter EE, Shimada Y, Li Y et al (1999) Mapping inner retinal function through enhancement of adaptation components in the M-ERG. Vision Science and Its Applications, OSA Technical Digest Series. Optical Society of America, Washington, DC, pp 52-55

170. Ho WC, Wong OY, Chan YC et al (2012) Sign-dependent changes in retinal electrical activity with positive and negative defocus in the human eye. Vision Res 52:47-53

171. Turnbull PRK, Goodman LK, Phillips JR (2020) Globalflash mfERG responses to local differences in spherical and astigmatic defocus across the human retina. Ophthalmic Physiol Opt 40:24-34

172. Fung MMY, Choi KY, Chan HHL (2021) The effect of simultaneous dual-focus integration on the global flash multifocal electroretinogram in the human eye. Ophthalmic Physiol Opt 41:171-178

173. Chen JC, Brown B, Schmid KL (2006) Retinal adaptation responses revealed by global flash multifocal electroretinogram are dependent on the degree of myopic refractive error. Vision Res 46:3413-3421

174. Ho W-C, Kee C-S, Chan HH-L (2012) Myopic children have central reduction in high contrast multifocal ERG Response, while adults have paracentral reduction in low contrast response. Invest Ophthalmol Vis Sci 53:3695-3702

175. Ho WC, Ng YF, Chu PH et al (2011) Impairment of retinal adaptive circuitry in the myopic eye. Vision Res 51:367-375

176. Ho W-C, Kee C-S, Chan HHL (2012) Myopia progression in children is linked with reduced foveal mfERG response. Invest Ophthalmol Vis Sci 53:5320-5325

177. Ho W-C, Kee C-S, Chan HHL (2011) Myopia progression in children is associated with regional changes in retinal function: a multifocal electroretinogram study. i-Perception 2:217-217

178. Li SZ-C, Yu W-Y, Choi K-Y et al (2017) Subclinical decrease in central inner retinal activity is associated with myopia development in children. Invest Ophthalmol Vis Sci 58:4399-4406

179. Chin MP, Chu PH, Cheong AM et al (2015) Human electroretinal responses to grating patterns and defocus changes by global flash multifocal electroretinogram. PLoS ONE 10:e123480

180. Rose KA, Morgan IG, Ip J et al (2008) Outdoor activity reduces the prevalence of myopia in children. Ophthalmology 115:1279-1285

181. Huang J, Wen D, Wang Q et al (2016) Efficacy comparison of 16 interventions for myopia control in children: a network meta-analysis. Ophthalmology 123:697-708

182. Lawrenson JG, Dhakal R, Verkicharla PK et al (2021) Interventions for myopia control in children: a living systematic review and network meta-analysis. Cochrane Database of Systematic Reviews

183. Liu YM, Xie P (2016) The safety of orthokeratology-a systematic review. Eye Contact Lens 42:35-42

184. Si J-K, Tang K, Bi H-S et al (2015) Orthokeratology for myopia control: a meta-analysis. Optom Vis Sci 92:252-257

185. González-Méijome JM, Faria-Ribeiro MA, Lopes-Ferreira DP et al (2016) Changes in peripheral refractive profile after orthokeratology for different degrees of myopia. Curr Eye Res 41:199-207

186. Kakita T, Hiraoka T, Oshika T (2011) Influence of overnight orthokeratology on axial elongation in childhood myopia. Invest Ophthalmol Vis Sci 52:2170-2174

187. Queirós A, González-Méijome JM, Jorge J et al (2010) Peripheral refraction in myopic patients after orthokeratology. Optom Vis Sci 87:323-329

188. Queirós A, Pereira-da-Mota AF, Costa J et al (2020) Retinal response of low myopes during orthokeratology treatment. J Clin Med 9:2649

189. Chua WH, Balakrishnan V, Chan YH et al (2006) Atropine for the treatment of childhood myopia. Ophthalmology 113:2285-2291

190. Chia A, Chua WH, Cheung YB et al (2012) Atropine for the treatment of childhood myopia: safety and efficacy of $0.5 \%, 0.1 \%$, and $0.01 \%$ doses (Atropine for the Treatment of Myopia 2). Ophthalmology 119:347-354

191. Chia A, Chua WH, Wen L et al (2014) Atropine for the treatment of childhood myopia: changes after stopping atropine $0.01 \%, 0.1 \%$ and $0.5 \%$. Am J Ophthalmol 157:451-457.e451 
192. Walline JJ, Lindsley K, Vedula SS et al (2011) Interventions to slow progression of myopia in children. Cochrane Database Syst Rev CD004916

193. Tong L, Huang XL, Koh AL et al (2009) Atropine for the treatment of childhood myopia: effect on myopia progression after cessation of atropine. Ophthalmology 116:572-579

194. Kothari M, Bhat D, Khadse N et al (2019) Changes in pattern electroretinogram after application of $0.01 \%$ atropine eye drops. Indian J Ophthalmol 67:309-310

195. Chia A, Li W, Tan D et al (2013) Full-field electroretinogram findings in children in the atropine treatment for myopia (ATOM2) study. Doc Ophthalmol 126:177-186

196. Lin L, Lan W, Liao Y et al (2013) Treatment outcomes of myopic anisometropia with $1 \%$ atropine: a pilot study. Optom Vis Sci 90:1486-1492
197. Luu CD, Lau AMI, Koh AHC et al (2005) Multifocal electroretinogram in children on atropine treatment for myopia. Br J Ophthalmol 89:151-153

198. Anders L-M, Heinrich SP, Lagrèze WA et al (2019) Little effect of $0.01 \%$ atropine eye drops as used in myopia prevention on the pattern electroretinogram. Doc Ophthalmol 138:85-95

199. Khanal S, Rathod SN, Phillips JR (2020) The acute effect of atropine eye drops on the human full-field electroretinogram. Doc Ophthalmol 142:315-328

200. Khanal S, Turnbull PRK, Lee N et al (2019) The effect of atropine on human global flash mfERG responses to retinal defocus. Invest Ophthalmol Vis Sci 60:218-225

Publisher's Note Springer Nature remains neutral with regard to jurisdictional claims in published maps and institutional affiliations. 